\title{
Microstructural evaluation and mechanical properties of 7075 aluminum alloy prepared by controlled diffusion solidification
}

\author{
Xiong Yang ${ }^{1}$, *Yuan-dong Li', Xiao-mei Luo', Hong-wei Zhou ${ }^{1,2}$, Qi-yong Cai ${ }^{1}$ Ming Li', Ying Ma ${ }^{1,2}$ \\ 1. State Key Laboratory of Advanced Processing and Recycling of Non-ferrous Metals, Lanzhou University of Technology, Lanzhou \\ 730050, China; \\ 2. Key Lab of Non-ferrous Metal Alloys and Processing, Ministry of Education, Lanzhou University of Technology, Lanzhou 730050, \\ China
}

\begin{abstract}
In the present work, 7075 aluminum alloy (Al-Zn-Mg-Cu) was produced by both conventional casting (CC) and controlled diffusion solidification (CDS) methods. Each sample was subjected to different heat-treatment conditions: as-cast, T4, and T6; and their microstructural and mechanical properties were investigated by optical microscopy (OM), scanning electron microscopy (SEM) and X-ray diffractometry (XRD). It was found that CDS promoted the formation of non-dendritic primary $\alpha$-Al phase and reduced shrinkage porosity, thus resulting in improved mechanical properties. In addition, the eutectic phase of the CDS samples mainly consisted of $T(\mathrm{Al}-\mathrm{Zn}$ $\mathrm{Mg}-\mathrm{Cu}$ ) phase, which manifested a well-developed lamellar eutectic structure. However, in the CC samples, the $T(\mathrm{Al}-\mathrm{Zn}-\mathrm{Mg}-\mathrm{Cu})$ phase was composed of rod-like eutectics. Moreover, the $\theta\left(\mathrm{Al}_{2} \mathrm{Cu}\right)$ eutectic contents in the CC samples were greater than those in the CDS samples. Each element in the CC samples had an obvious change in the grain boundary, whereas the change in element content in the CDS samples was gradual. Therefore, the non-dendritic morphology of the primary phase and the presence of rod-like eutectics in the matrix of the CDS samples led to enhanced tensile strength and elongation under different heat treatment conditions.
\end{abstract}

Key words: primary $\alpha-A$ I phase; eutectic phase; solute atoms; tensile strength; elongation

CLC numbers: TG146.21 Document code: A Article ID: 1672-6421(2019)04-238-10

$\mathrm{T}$ he 7075 aluminum alloy $(\mathrm{Al}-\mathrm{Zn}-\mathrm{Mg}-\mathrm{Cu})$ is widely used in aerospace and automotive industries due to its high strength to weight ratio and excellent ductility ${ }^{[1,2]}$. However, it does not perform well in terms of mechanical properties due to microstructural defects, such as macrosegregation and hot tearing ${ }^{[3]}$. Generally, the mechanical properties of Al alloys can be improved by grain refinement ${ }^{[4]}$, which increases the capability of plastic deformation and reduces the tendency of hot cracking in $7075 \mathrm{Al}$ alloy ingot. In order to achieve near-net shaped casting of Al alloys, different methods, such as the addition of grain refiners ${ }^{[5]}$ and microalloying elements ${ }^{[6]}$, electromagnetic stirring ${ }^{[7]}$, and ultrasonic vibration ${ }^{[8]}$ have been implemented. However, grain refiners and trace alloy elements (Ti, Zr, Sc) have limited effects on grain

\section{* Yuan-dong Li}

Male, born in 1971, Ph. D, Professor. His research mainly focuses on the semisolid metal processing of nonferrous alloys.

E-mail: liyd_lut@163.com

Received: 2019-04-28; Accepted: 2019-06-05 refinement in $7075 \mathrm{Al}$ alloy, whereas electromagnetic stirring and ultrasonic vibration require complicated technologies. Hence, a new casting route is required to improve the mechanical properties of $\mathrm{Al}$ alloys.

Controlled diffusion solidification (CDS) is a novel casting method. The concept of CDS has come from diffusion solidification (DS), which was first applied in steel casting by Langford and Apelian ${ }^{[9,10]}$ in 1978 and then further developed by Saha et al. ${ }^{[11]}$ and Abbas et al. ${ }^{[12]}$. In CDS, two precursor melts with different chemical compositions and temperatures are mixed together to obtain a resultant alloy. This method can result in a fine and uniform primary $\alpha-\mathrm{Al}$ phase with non-dendritic morphology. Moreover, it has a better feeding efficiency and can reduce hot tearing and shrinkage porosity. In addition, CDS is a simple and low-cost technology. In recent years, researchers have employed CDS to study the formation mechanism of the primary $\alpha$-Al phase in Al-Cu wrought alloys ${ }^{[13]}$ and Al-Si hypereutectic alloys ${ }^{[14,15]}$. However, very few reports are available on the effects of CDS on 7075 Al alloy. Especially, the influences of solute gradient 
and temperature gradient on eutectic phase are not discussed elaborately in previous studies. In the present study, the liquidliquid mixing methods (conventional casting (CC) and CDS) were adopted to fabricate $7075 \mathrm{Al}$ alloy, and a comparison between solute gradient and temperature gradient of the $\mathrm{CC}$ and CDS samples was carried out.

\section{Experiment procedures}

\subsection{Materials and methods}

In the present experiment, two precursor melts, Al-Zn11.2-Mg5$\mathrm{Cu} 3$ (wt.\%) and pure Al, were used to prepare the 7075 alloy. According to the content of the precursor-melts, the mass ratio of the two precursor melts should be 1:1. The temperatures of the melts were measured by a K-type thermocouple, as shown in Table 1 .

Table 1: Temperature of melts

$\begin{array}{ccc}\text { Alloy } & \begin{array}{c}\text { Temperature } \\ \text { before mixing }\end{array} & \begin{array}{c}\text { Pouring } \\ \text { temperature }\end{array} \\ \text { Al } & 660^{\circ} \mathrm{C} & - \\ \mathrm{Al}-11.2 \% \mathrm{Zn}-5 \% \mathrm{Mg}-3 \% \mathrm{Cu} & 620^{\circ} \mathrm{C} & - \\ 7075 & - & 637^{\circ} \mathrm{C}\end{array}$

Two SG-7.5-10 electric-resistance furnaces were employed to heat the precursor melts. The \#1 electric-resistance furnace was used to melt Al-Zn11.2-Mg5-Cu3 alloy at $720{ }^{\circ} \mathrm{C}$. Then $1 \%$ $\mathrm{C}_{2} \mathrm{Cl}_{6}$ was added into the melt for refinement. The \#2 electricresistance furnace was utilized to melt pure $\mathrm{Al}$ at $760{ }^{\circ} \mathrm{C}$. Furthermore, pure $\mathrm{Al}\left(660^{\circ} \mathrm{C}\right)$ was poured into the $\mathrm{Al}-\mathrm{Zn} 11.2$ $\mathrm{Mg} 5-\mathrm{Cu} 3$ alloy $\left(620^{\circ} \mathrm{C}\right)$, and the two melts were then mixed quickly by stirring. When the temperature of the alloy dropped to $637^{\circ} \mathrm{C}$, the mixed melt was poured into a permanent mold (preheated at $200{ }^{\circ} \mathrm{C}$ ) to obtain a $\Phi 15 \mathrm{~mm} \times 150 \mathrm{~mm}$ cylindrical ingot. Figure 1 shows the controlled diffusion solidification (CDS) casting process.

\subsection{Characterization}

The electrolytic corrosion experiment was performed in an RXN-605D system for $40 \mathrm{~s}$. The corrosion liquid was

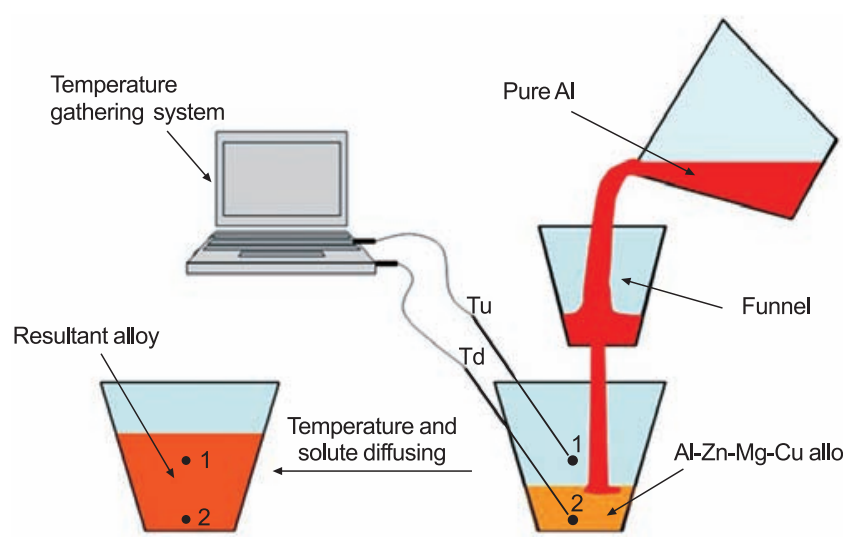

Fig. 1: Schematic illustration of CDS casting process

composed of perchloric acid and ethanol in a ratio of 1:9. The morphologies of corroded surfaces were observed by a MEF-3 optical microscope (OM). The constitutions of the CDS and CC samples were detected by a D/Max-2400 X-ray diffractometer (XRD) and a FEG450 scanning electron microscope (SEM). Tensile tests were performed in a WDW-100D testing machine at a strain rate of $2 \mathrm{~mm} \cdot \mathrm{min}^{-1}$. Cylindrical tensile specimens with a diameter of $10 \mathrm{~mm}$ were subjected to different heat treatment conditions including T4 and T6 heat treatment. Both T4 and T6 samples were heated to $470{ }^{\circ} \mathrm{C}$ and held for different times (T4 for $20 \mathrm{~min}, 40 \mathrm{~min}, 60 \mathrm{~min}$ respectively and T6 for $60 \mathrm{~min}$ ) followed by water quenching. For T4 heat treatment, the samples were naturally aged at room temperature for 30 days. For T6 heat treatment, the samples were artificially aged to $120^{\circ} \mathrm{C}$, held for $12 \mathrm{~h}$ and finally air cooled.

\section{Results}

\subsection{Microstructures of CC and CDS samples}

It is clear from Fig. 2 that both the primary $\alpha-\mathrm{Al}$ phase and the eutectic microstructure exist in the $\mathrm{CC}$ and $\mathrm{CDS}$ samples. The primary $\alpha$-Al phase of the CC sample shows a well-developed dendritic morphology with an average grain size of $>200 \mu \mathrm{m}$ [Fig. 2(a)], whereas a non-dendritic morphology with an average grain size of $<100 \mu \mathrm{m}$ was observed in the primary $\alpha$-Al phase of the CDS sample [Fig. 2(b)].

Figure 3 shows the SEM images of both CC and CDS
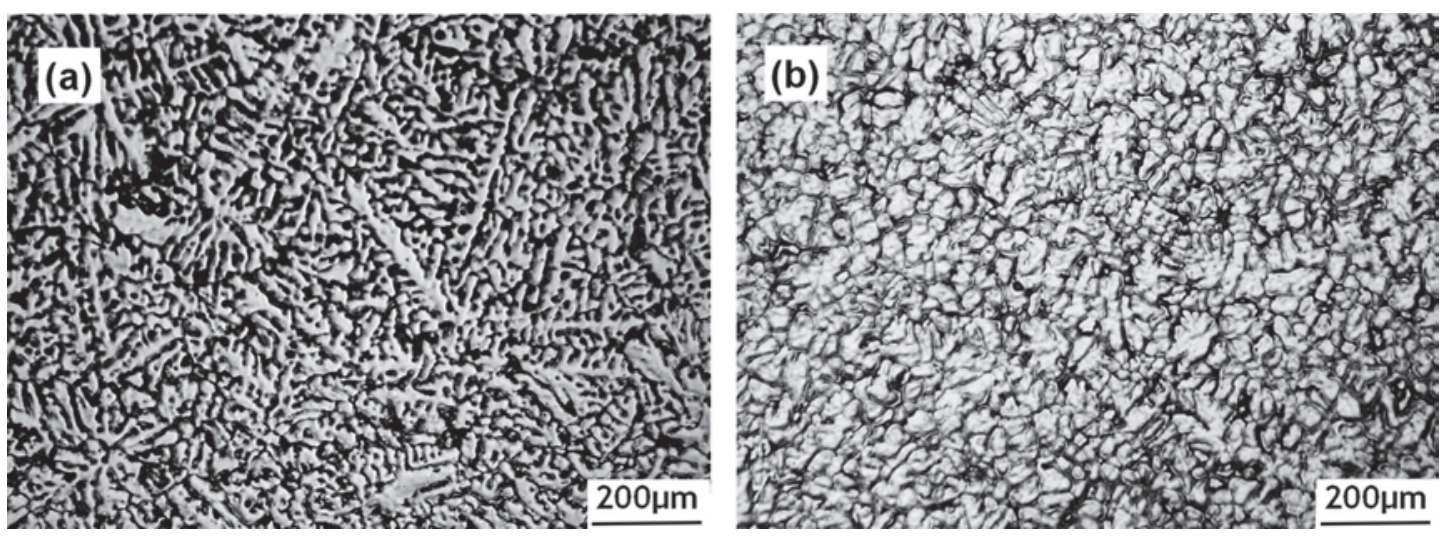

Fig. 2: Solidification microstructure of 7075 aluminum alloy: (a) CC; (b) CDS 
samples. A large amount of shrinkage porosities was observed in the CC sample [Fig. 3(a)]. Results calculated using the ImagePro Plus 6.0 software indicated that the content of shrinkage porosity in CDS sample $(0.1 \%)$ is less than that in CC sample $(1.2 \%)$. The dendritic morphology of the primary $\alpha$-Al phase deteriorated the mechanical properties of the ingot and produced considerable residual stress during the solidification process. Moreover, the interspaces of dendrites in the $\mathrm{CC}$ sample were larger than those in the CDS sample; thus, eutectics could not completely fill all interspaces. The white sections in Fig. 3 represent eutectic phases consisted of the primary $\alpha$-Al phase and the $T(\mathrm{Al}-\mathrm{Zn}-\mathrm{Mg}-\mathrm{Cu})$ phase. It is noticeable from Fig. 3(a) that the distributions and the widths of the eutectic phases were non-uniform. In contrast, the primary $\alpha$-Al phases in the CDS sample yields a homogeneous, non-dendritic morphology with a small amount of shrinkage porosities, thus resulting in enhanced feeding efficiency. The distribution and the width of the eutectic phases were found to be almost uniform.
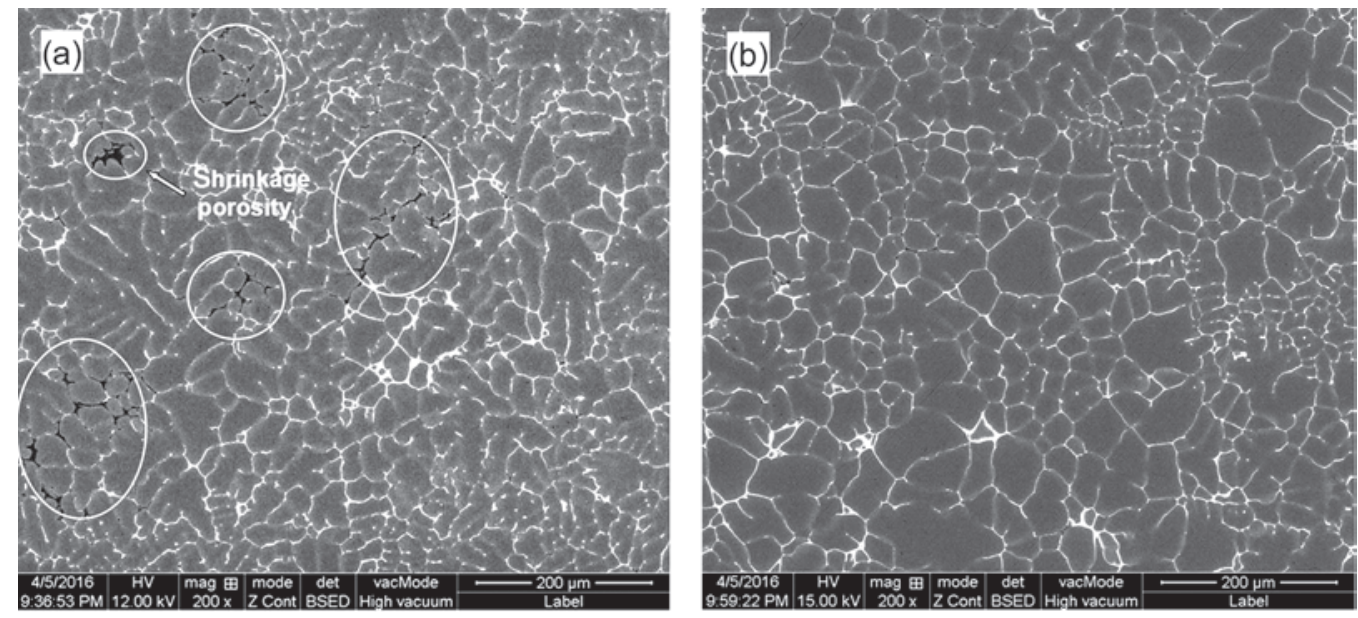

Fig. 3: SEM images of solidification microstructure of 7075 alloy: (a) CC; (b) CDS

\subsection{XRD analysis}

Figure 4 shows the XRD results (scanning range was from $20^{\circ}$ to $80^{\circ}$ ) for both $\mathrm{CC}$ and CDS samples. It is found that both samples are composed of primary $\alpha$-Al phase, $\eta\left(\mathrm{MgZn}_{2}\right)$ phase, and $\theta\left(\mathrm{Al}_{2} \mathrm{Cu}\right)$ phase ${ }^{[16,17]}$. The diffraction intensity of the $\alpha-\mathrm{Al}$ phase was found to be higher than that of the other two phases, which indicates that the primary $\alpha$-Al phase is the main phase in the matrix of $7075 \mathrm{Al}$ alloy. The amounts of $\eta\left(\mathrm{MgZn}_{2}\right)$ and $\theta\left(\mathrm{Al}_{2} \mathrm{Cu}\right)$ phases in the CDS sample are slightly higher than those in the $\mathrm{CC}$ sample. However, the $T(\mathrm{Al}-\mathrm{Zn}-\mathrm{Mg}-\mathrm{Cu})$ phase was not observed in any sample, which can be attributed to the similar hexagonal crystal structure of $T(\mathrm{Al}-\mathrm{Zn}-\mathrm{Mg}-\mathrm{Cu})$ and $\eta\left(\mathrm{MgZn}_{2}\right)$ phases. The atomic sizes of $\mathrm{Al}, \mathrm{Zn}, \mathrm{Mg}$, and $\mathrm{Cu}$ were measured as $0.143,0.133,0.160$, and $0.128 \mathrm{~nm}$, respectively.

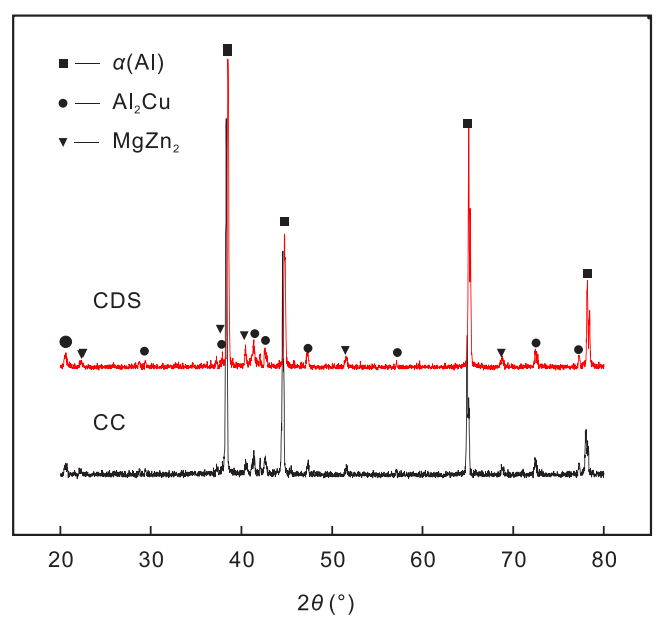

Fig. 4: XRD pattern of CC and CDS for 7075 aluminum alloy
As the atomic sizes of $\mathrm{Al}$ and $\mathrm{Cu}$ are similar with $\mathrm{Zn}$, they easily exchanged the $\mathrm{Zn}$ atoms in the $\eta\left(\mathrm{MgZn}_{2}\right)$ phase, which is further transformed into the $T(\mathrm{Al}-\mathrm{Zn}-\mathrm{Mg}-\mathrm{Cu})$ phase ${ }^{[18,19]}$. Hence, the XRD peak of the $\eta\left(\mathrm{MgZn}_{2}\right)$ phase contains the data of both $T(\mathrm{Al}-\mathrm{Zn}-\mathrm{Mg}-\mathrm{Cu})$ and $\eta\left(\mathrm{MgZn}_{2}\right)$ phases.

\subsection{Segregation of solute elements}

The line-scanning images of the CC and CDS samples are shown in Fig. 5. The solute gradient at the grain boundary in the CDS sample [Fig. 5(a)] is much smaller than that in the CC sample [Fig. 5(b)].

The high concentrations of $\mathrm{Zn}, \mathrm{Mg}$, and $\mathrm{Cu}$ atoms in the eutectic phases of both CC and CDS samples easily induce phase segregation. In the eutectic phase, the contents of $\mathrm{Cu}$ and $\mathrm{Mg}$ atoms are respectively the greatest and the least, and this phenomenon is relevant to the environment-sensitive embedding energy ${ }^{[20]}$ :

$$
E_{\mathrm{ESE}}=\left[E_{i}-(n-1) E_{\text {self }}-E_{\text {iself }}\right]-\left(E_{\mathrm{cl}}-n E_{\mathrm{self}}\right)
$$

where $E_{i}$ is the structural energy with solute atoms, $E_{\mathrm{cl}}$ is the structural energy without solute atoms, $n$ denotes atomicity, $E_{\text {self }}$ is the matrix atomic energy, and $E_{\text {iself }}$ is the matrix-solute atomicity energy. Therefore, for a large value of environmentsensitive embedding energy, more solute atoms are influenced by the environment around them, thus, they become unstable and diffuse to the stable environment where the environmentsensitive embedding energy is low. Liu ${ }^{[21]}$ calculated the environment-sensitive embedding energies of $\mathrm{Al}, \mathrm{Zn}, \mathrm{Mg}$, and $\mathrm{Cu}$ atoms (Table 2). It indicates that the environmentsensitive embedding energy of $\mathrm{Zn}$ atoms in the $\alpha$-Al grain 

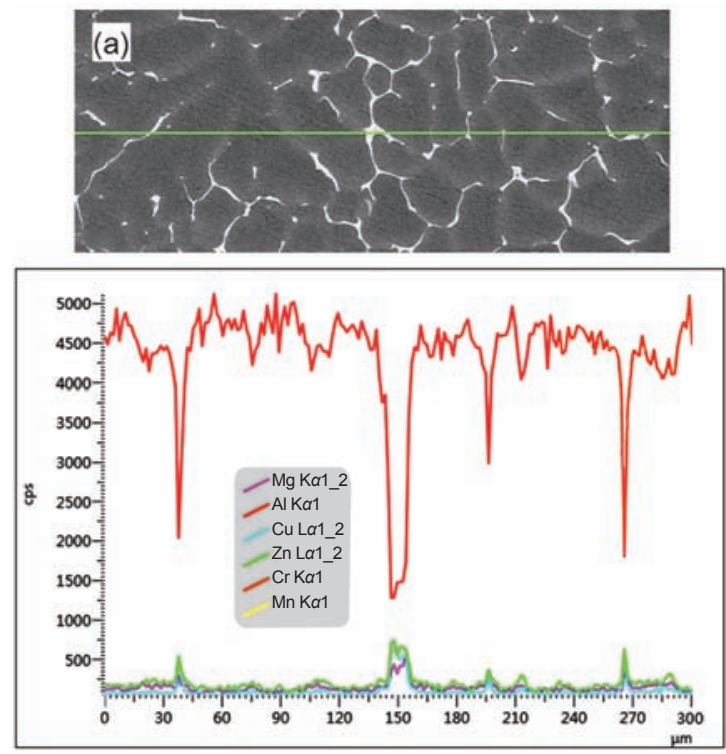

Fig. 5: Line scanning images: (a) CC; (b) CDS
Table 2: Environment-sensitive embedding energy of $\mathrm{Zn}$, $\mathrm{Mg}, \mathrm{Cu}$ at grain boundary and in $\alpha-\mathrm{Al}(\mathrm{eV})^{[21]}$

\begin{tabular}{|cccc|}
\hline Position & $\mathrm{Zn}$ & $\mathrm{Mg}$ & $\mathrm{Cu}$ \\
\hline At boundary & 1.6452 & 21.9444 & 22.6892 \\
\hline In $\alpha-\mathrm{Al}$ & 1.1292 & 22.5959 & 23.0077 \\
\hline
\end{tabular}

matrix is lower than that at the $\alpha-\mathrm{Al}$ grain boundary, so $\mathrm{Zn}$ atoms are embedded firmly in the $\alpha$-Al grain matrix. The surface-scanning result reveals that the amount of $\mathrm{Zn}$ atoms in the $\alpha$-Al grain matrix is the highest. Moreover, the environmentsensitive embedding energies of $\mathrm{Mg}$ and $\mathrm{Cu}$ atoms are higher than the $\mathrm{Zn}$ atoms. Hence, the $\mathrm{Mg}$ and $\mathrm{Cu}$ atoms were indicated lower solid solubility in the $\alpha$-Al grain matrix. Furthermore, the environment-sensitive embedding energy of $\mathrm{Cu}$ atoms in the $\alpha-\mathrm{Al}$ grain matrix is the highest; hence, their solid solubility is
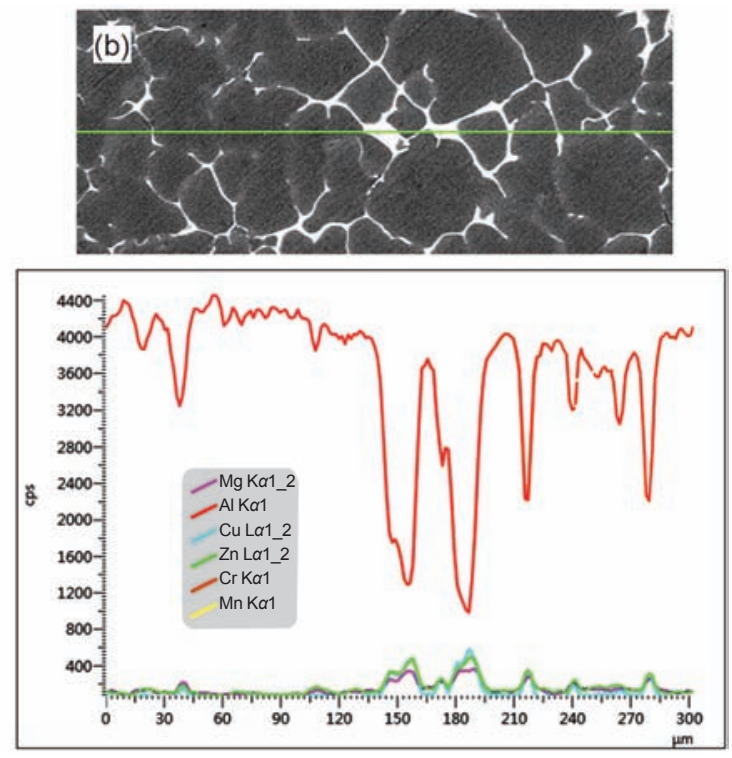

found to be the lowest.

The scanning data of the primary $\alpha$-Al phases and the eutectic phases of the CC and the CDS (Fig. 7) samples are shown in Table 3. It is discernible that the amount of $\mathrm{Al}$ atoms decreases gradually from the center of the primary $\alpha$-Al phases to the eutectic phases, whereas the contents of $\mathrm{Zn}, \mathrm{Mg}$, and $\mathrm{Cu}$ atoms increase gradually from the center of the primary $\alpha$-Al phases to the eutectic phases. Moreover, the contents of $\mathrm{Zn}, \mathrm{Mg}$, and $\mathrm{Cu}$ atoms in the eutectic phases of the CDS sample (point $\mathrm{D}_{1}$ ) are found to be higher than those in the eutectic phases of the CC sample (point D). However, at the center of the primary $\alpha$-Al phases, the amounts of $\mathrm{Zn}, \mathrm{Mg}$, and $\mathrm{Cu}$ atoms in the CDS sample (point $\mathrm{A}_{1}$ ) are lower than those in the $\mathrm{CC}$ sample (point $\mathrm{A}$ ). Furthermore, at the boundary of the primary $\alpha$-Al phases, the contents of $\mathrm{Zn}, \mathrm{Mg}$, and $\mathrm{Cu}$ atoms in the CDS sample (point $\mathrm{C}_{1}$ ) are higher than those in the $\mathrm{CC}$ sample (point $\mathrm{C}$ ).
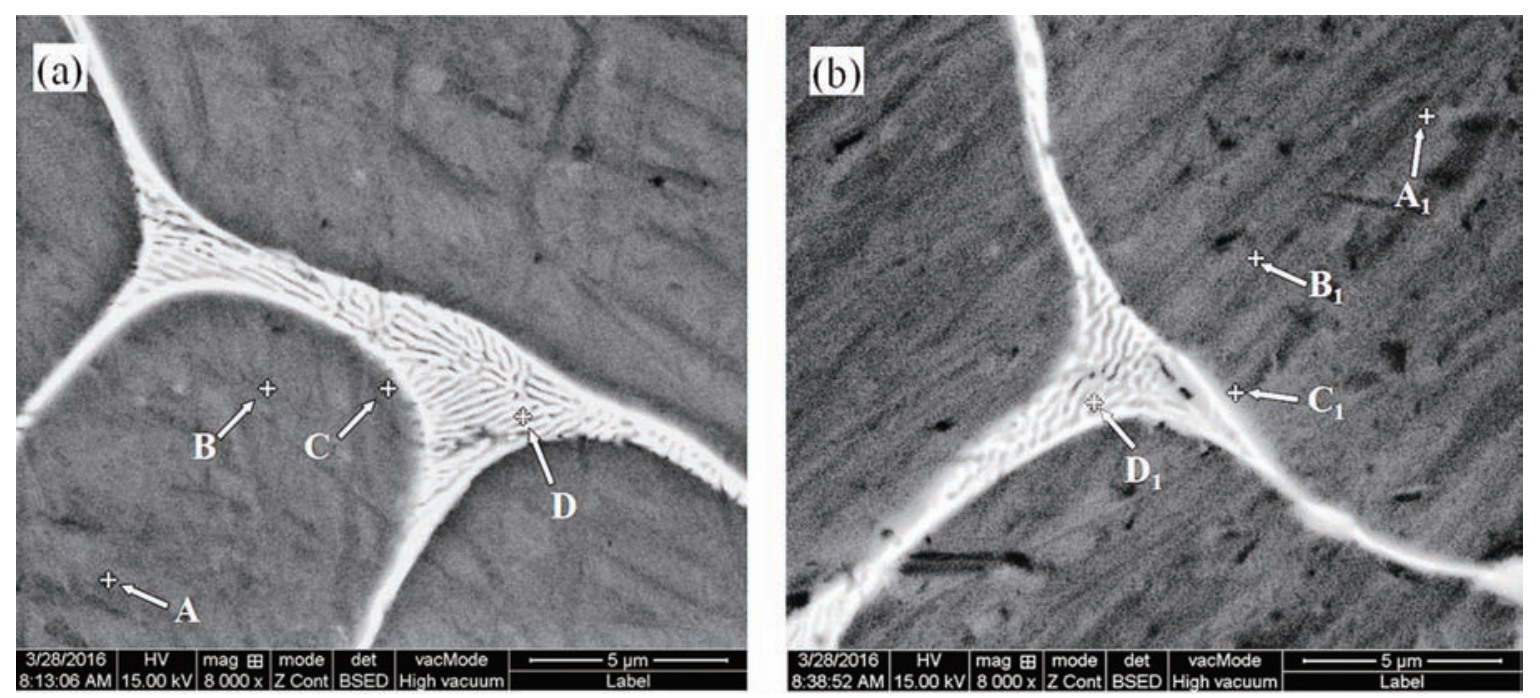

Fig. 6: Point scanning images: (a) CC; (b) CDS 
Table 3: Chemical composition of each phase in $\mathrm{CC}$ and CDS

\begin{tabular}{ccccc} 
& \multicolumn{5}{c}{ Mole fraction $(\%)$} \\
Zone & Al & Zn & Mg & Cu \\
\hline A & 94.8 & 3.9 & 1.3 & 0 \\
B & 92.4 & 4.7 & 2.3 & 0.6 \\
C & 85.0 & 8.6 & 3.5 & 2.9 \\
D & 42.7 & 26.8 & 12.3 & 18.2 \\
A $_{1}$ & 96.2 & 2.8 & 1.0 & 0 \\
$B_{1}$ & 92.5 & 5.3 & 1.8 & 0.4 \\
C $_{1}$ & 82.2 & 10.5 & 3.9 & 3.4 \\
$D_{1}$ & 37.8 & 27.6 & 13.2 & 21.4
\end{tabular}
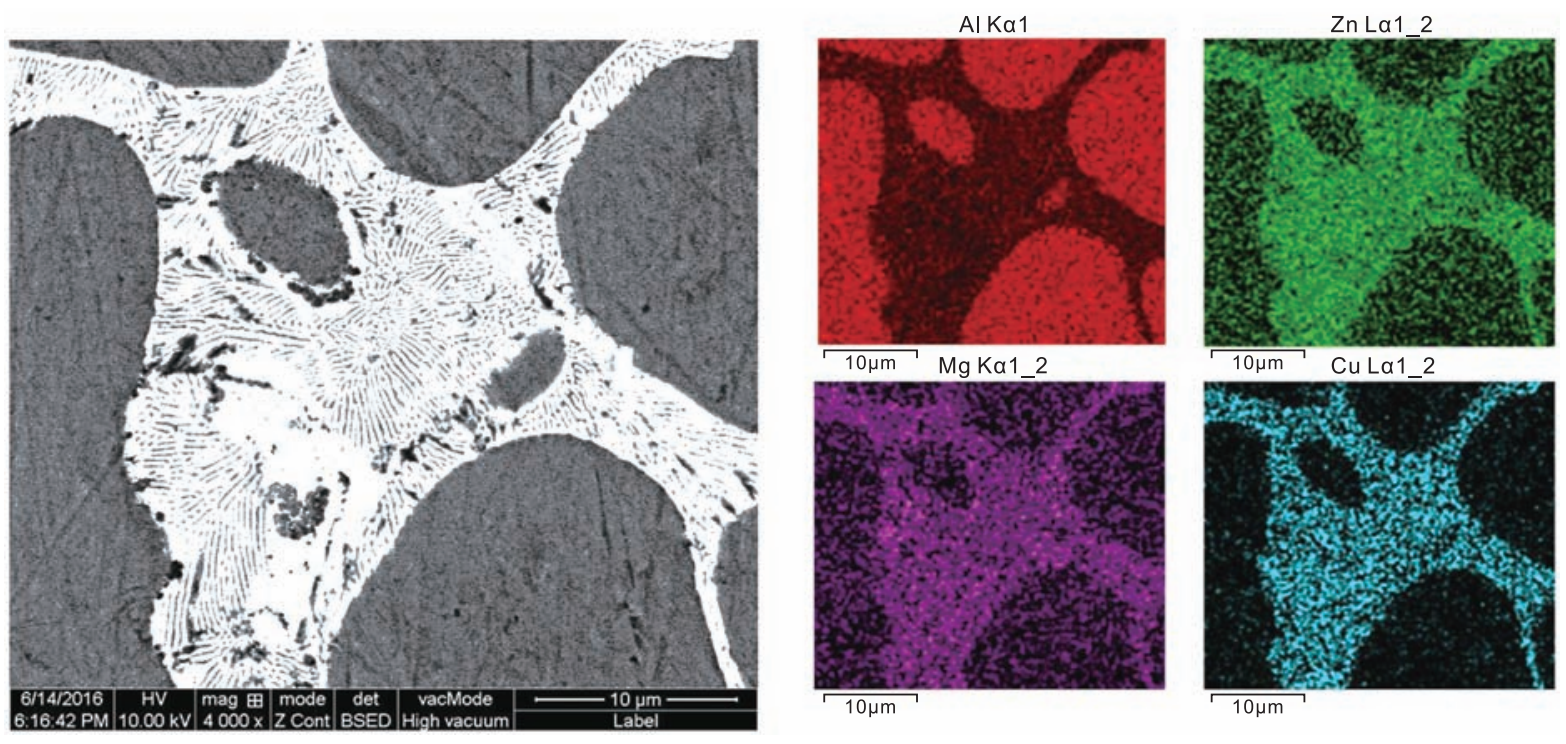

Fig. 7: Surface scanning images of CC
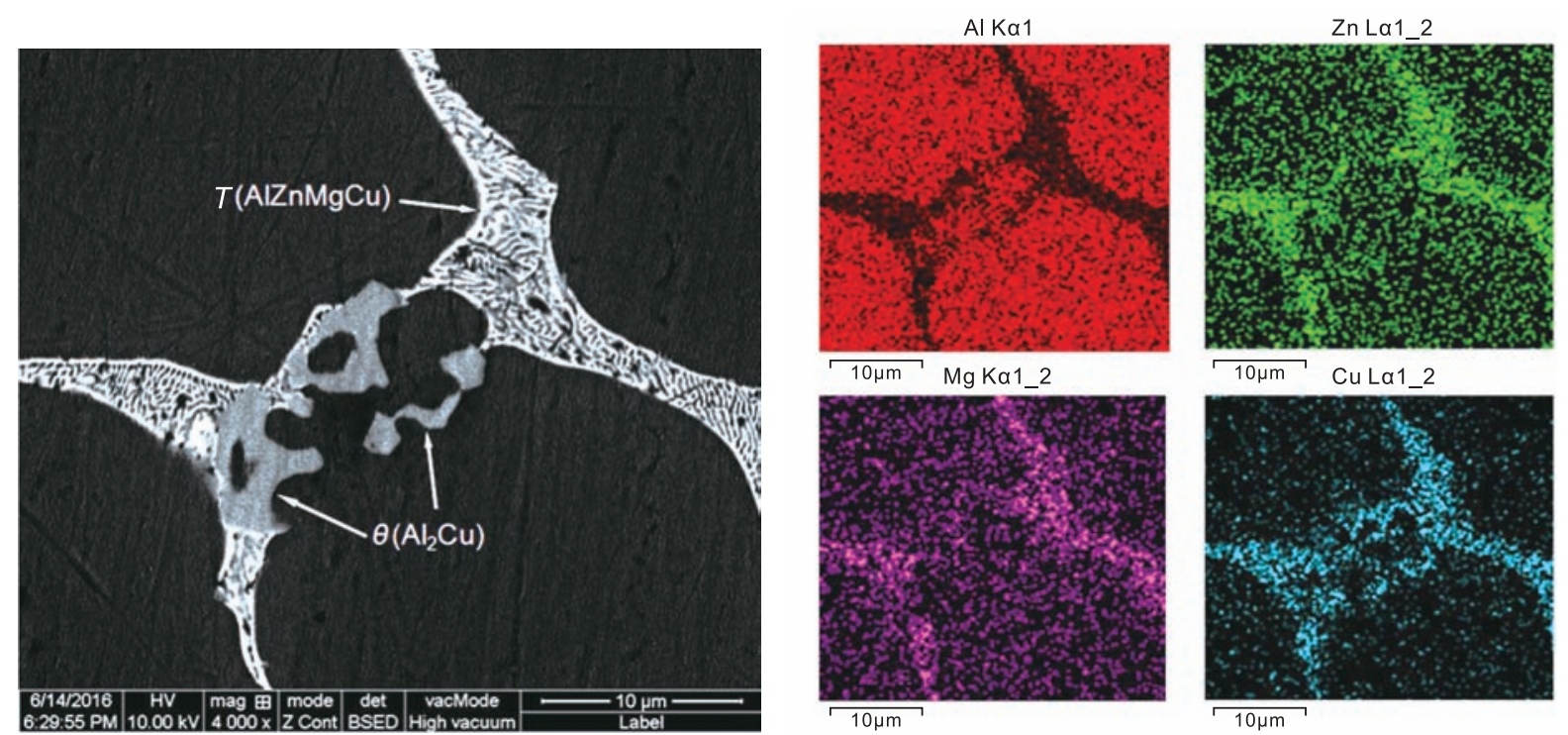

Fig. 8: Surface scanning image of CDS 
such, more $\mathrm{Cu}$ atoms concentrated in the dendrite spaces of the CDS sample. When the temperature reached $470{ }^{\circ} \mathrm{C}$, the eutectic reaction occurred:

$$
L \rightarrow \alpha-\mathrm{Al}+T(\mathrm{Al}-\mathrm{Zn}-\mathrm{Mg}-\mathrm{Cu})
$$

Moreover, the $T(\mathrm{Al}-\mathrm{Zn}-\mathrm{Mg}-\mathrm{Cu})$ phases are easily generated by heterogeneous nucleation, which can be seen in Fig. 7 .

The $T(\mathrm{Al}-\mathrm{Zn}-\mathrm{Mg}-\mathrm{Cu})$ phases generally exist in the dendrite spaces of 7 series $\mathrm{Al}$ alloys. When the content of $\mathrm{Cu}$ atoms is low, the eutectic phases are mainly lamellar; however, when $\mathrm{Cu}$ content is high, the eutectic phases are rod-like.
For example, the eutectic phases of 7449 and $7056 \mathrm{Al}$ alloys are lamellar eutectics due to their low $\mathrm{Cu}$ contents (1.90 and 1.63 , respectively), whereas the eutectic phases of 7136 and $7095 \mathrm{Al}$ alloys are rod-like due to their high $\mathrm{Cu}$ contents $(2.16$ and 2.24 , respectively $)^{[17]}$. In the present experiment, the $\mathrm{Cu}$ content in $7075 \mathrm{Al}$ alloy was 1.60. It is found that the eutectic phases of the CC sample are mainly lamellar eutectics (Fig. 9), whereas the eutectic phases of the CDS specimen are rodlike (Fig. 10). This indicates that the CDS sample possessed more $\mathrm{Cu}$ contents in the eutectic phases as compared to the CC sample.
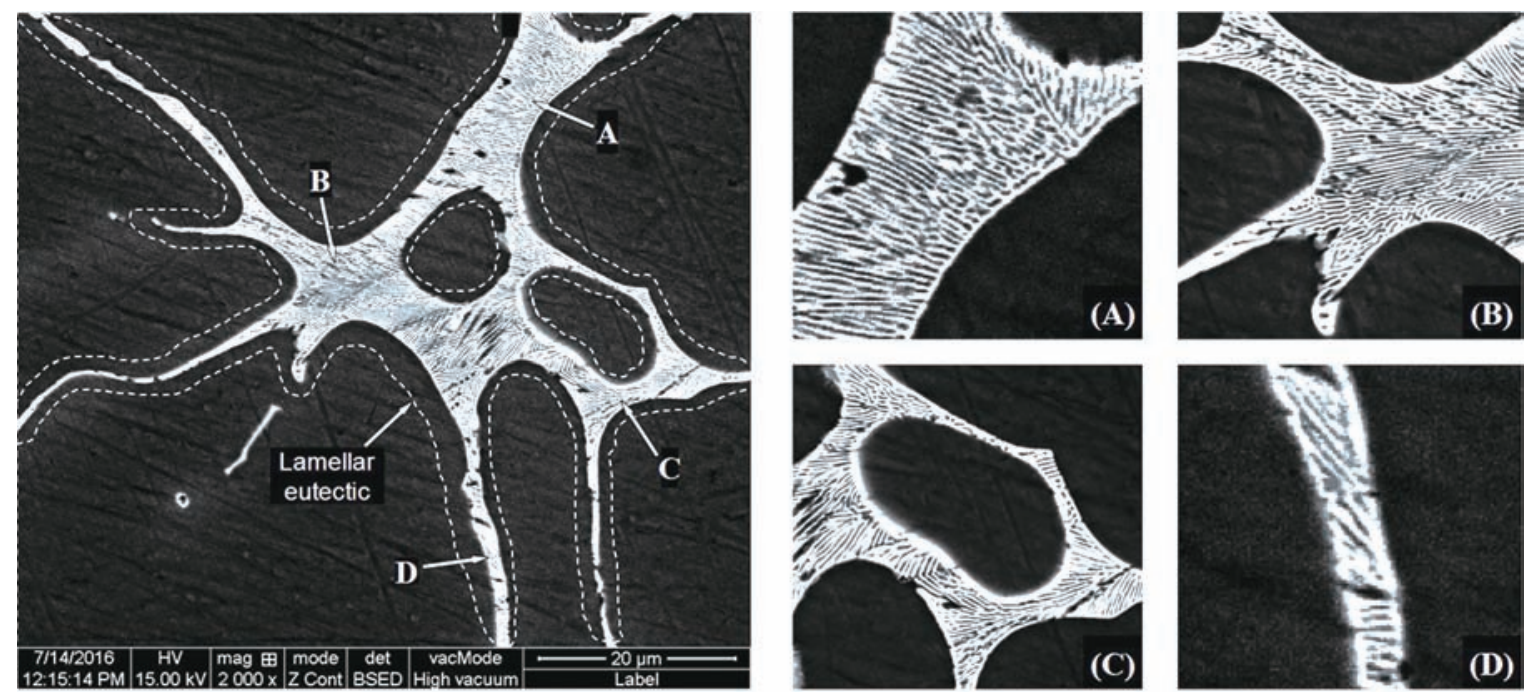

Fig. 9: Microstructure of eutectic phase by CC
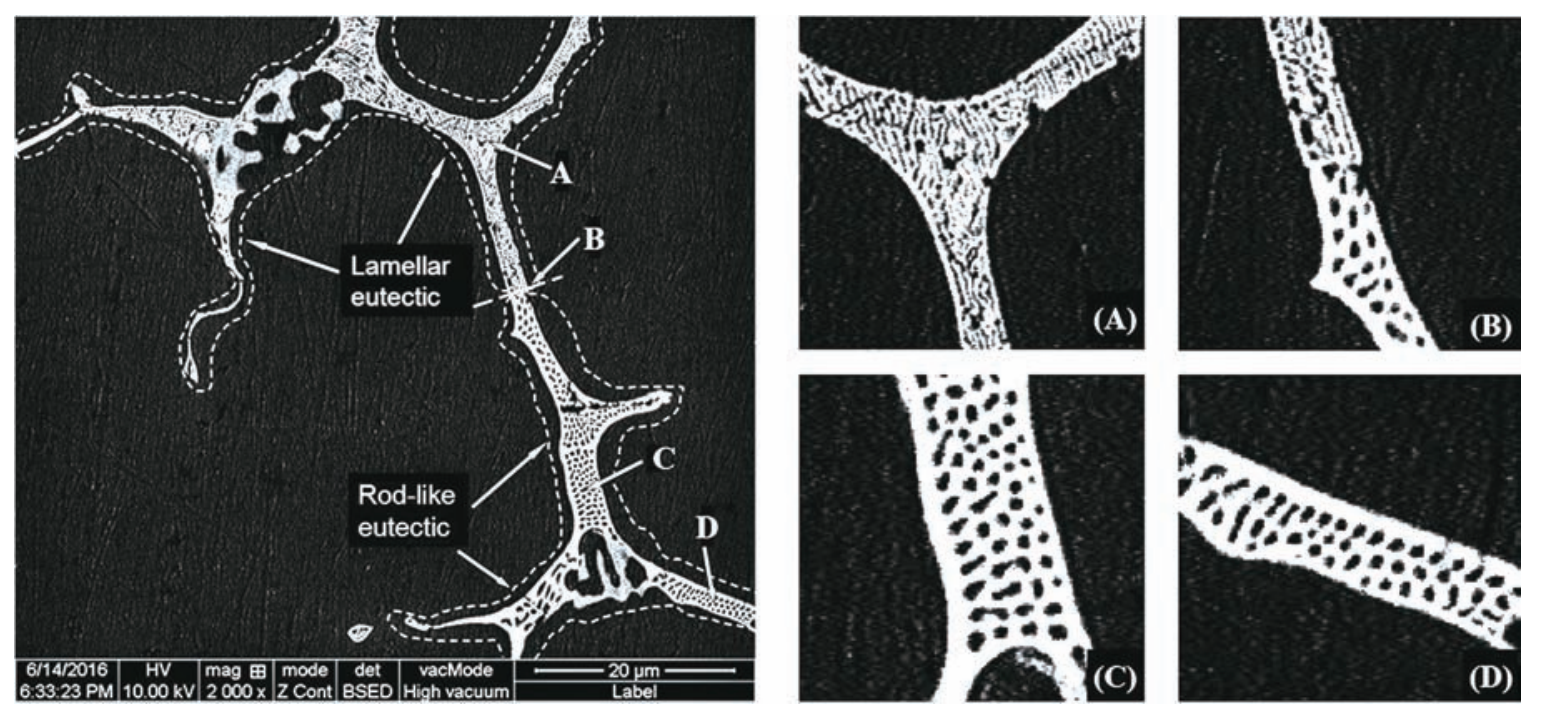

Fig. 10: Microstructure of eutectic phase by CDS

Figure 11 shows the changes in tensile strength [Fig. 11(a)], yield strength [Fig. 11(b)] and elongation [Fig. 11(c)] of the samples under different heat-treatment conditions. The average tensile strength and yield strength of the as-cast CDS samples (164 MPa and $127 \mathrm{MPa}$ ) were much higher than that of the CC samples (122 MPa and $97 \mathrm{MPa})$. The significant improvement in tensile strength and yield strength of the CDS samples can be ascribed to the following reasons: (i) In the final stage of solidification, the primary phases of the CC samples mainly consisted of dendrites, which generated more shrinkage porosities and lowered the feeding efficiencies of the eutectic phases. However, the primary phases of the CDS samples were composed of nearly sphere-like non-dendrites, which showed excellent feeding efficiencies because of their higher diffusivities. (ii) As compared to the CDS samples, the CC samples generated more residual stresses during solidification. 

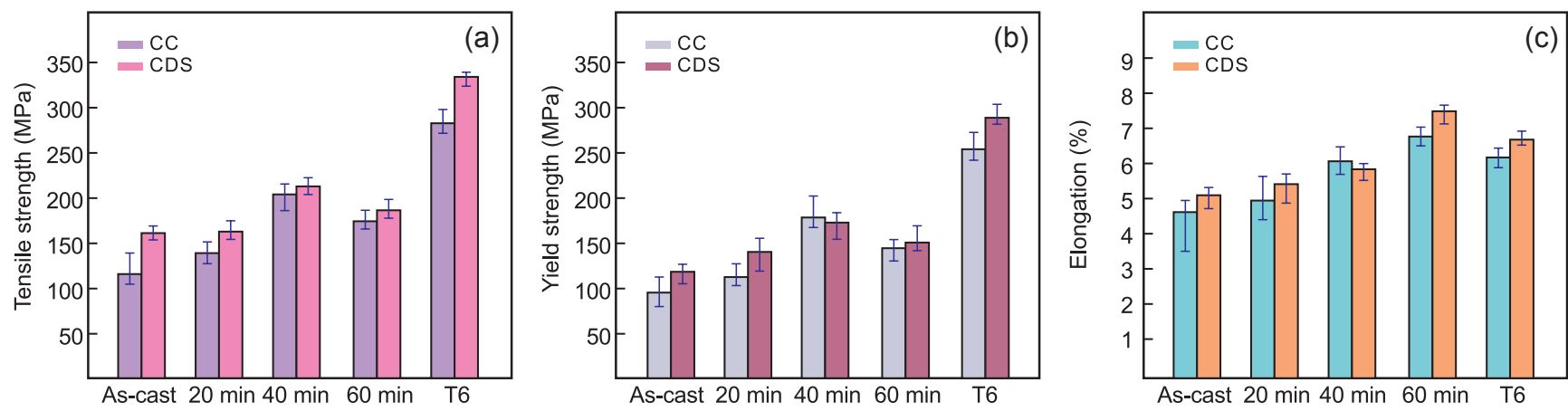

Fig. 11: Tensile strength (a), yield strength (b) and elongation (c) for CDS and CC under different heat treatment conditions

Under T4 treatment for $40 \mathrm{~min}$, the CC and the CDS samples reached the maximum tensile strengths of $205 \mathrm{MPa}$ and 220 $\mathrm{MPa}$, respectively. It is also worth noting that the $\mathrm{CC}$ and the CDS specimens had the best tensile strengths (281 MPa and $340 \mathrm{MPa}$, respectively) and yield strengths (251 MPa and $285 \mathrm{MPa}$, respectively) under T6 heat treatment; however, obvious reductions in their elongations $(6.08 \%$ and $6.57 \%$, respectively) were also noticed. As the matrix produced many second-phase particles, these precipitates inhibited the dislocation motion and resulted in a strengthening effect which, in turn, caused a decrease in ductility and reduced the elongations of the samples.

Figure 12 shows the fracture morphologies of the samples under different heat-treatment conditions. The as-cast CC sample [Fig.12(a)] yielded many more shrinkage porosities as compared to the CDS sample [Fig.12(b)]. Under T4 treatment for $60 \mathrm{~min}$, the fatigue fracture of the alloy exhibited a mixedrupture characteristic of quasi-cleavage and dimples. In contrast, under as-cast and T6 heat treatment, the samples were dominated by brittle fracture. Moreover, a considerable amount of $\eta\left(\mathrm{MgZn}_{2}\right)$ phases was generated after the aging treatment, and these $\eta\left(\mathrm{MgZn}_{2}\right)$ phases inhibited the movements of dislocations and reduced the toughness of the samples. Hence, the T4 treatment for 60 min caused the highest elongation and the T6 treatment yielded the best tensile strength.

The fracture surface of lamellar eutectics was almost a smooth plane [Fig. 13(a)], whereas an unsmooth fracture surface was obtained for rod-like eutectics [Fig. 13(b)]. In addition, lamellar eutectics acted as crack initiation sites and led to relatively poor tensile properties. In contrast, rod-like
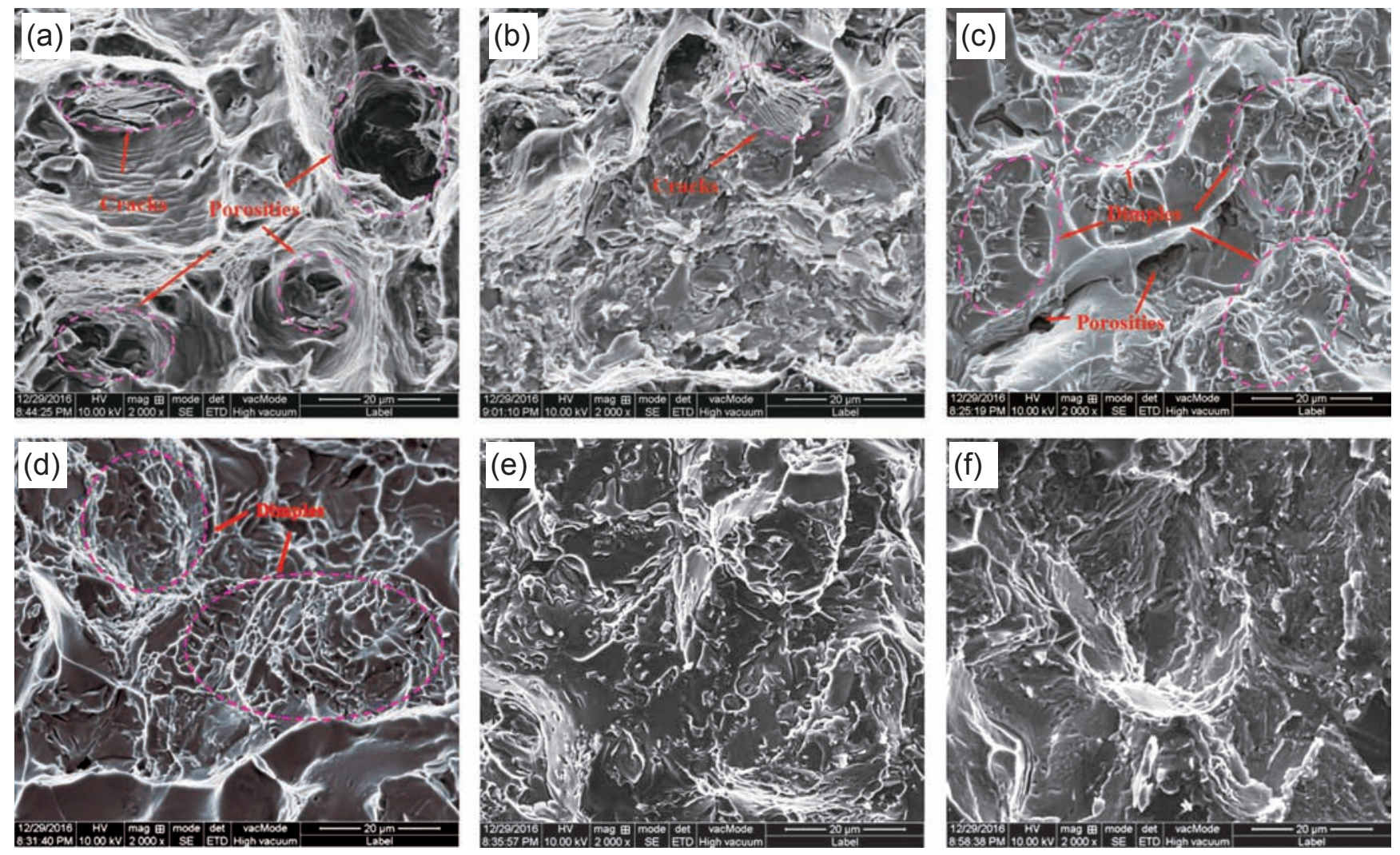

Fig. 12: SEM images of tensile fracture morphology of CC and CDS under different conditions: (a) as-cast CC; (b) as-cast CDS; (c) CC under T4 for $60 \mathrm{~min}$; (d) CDS under T4 for $60 \mathrm{~min}$; (e) CC under T6; (f) CDS under T6 

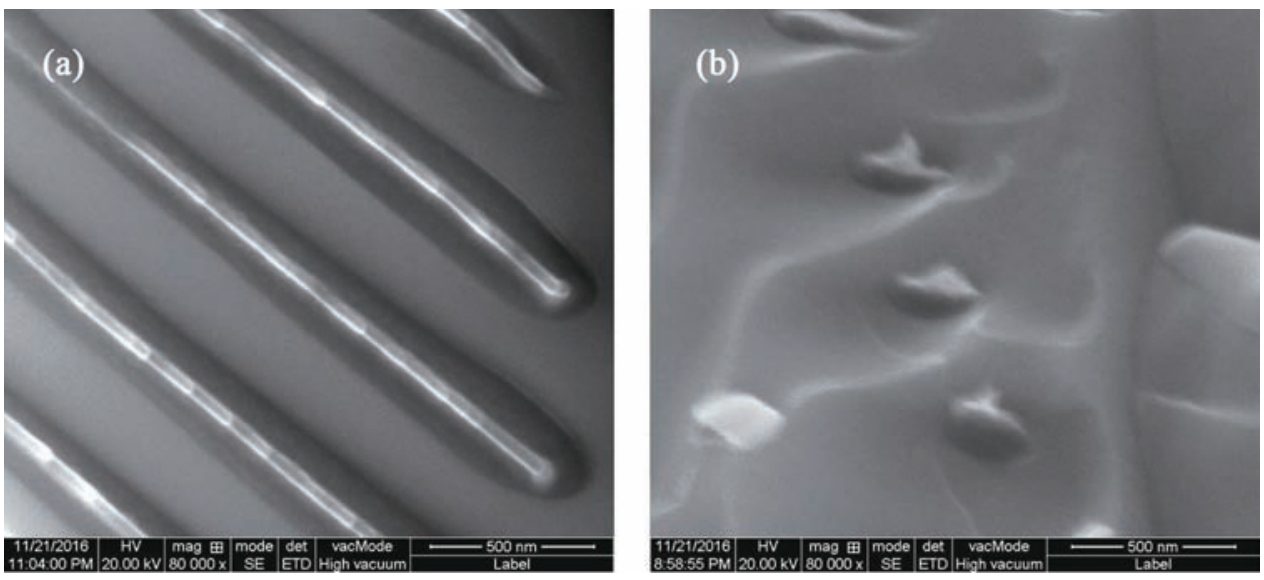

Fig. 13: Lamellar (a) and rod-like (b) eutectics of 7075 alloy after tensile testing

eutectic phases had excellent tensile-force resisting capacities. Furthermore, the contents of rod-like eutectics in the CDS samples were higher than those in the CC samples; hence, in the initial stage of tensile testing, the CDS samples resisted the tensile force and impeded the formation of cracks.

\section{Discussion}

\subsection{Thermodynamic condition}

Baker and Cahn ${ }^{[22]}$ used the Gibbs free-energy variational diagram to show how Gibbs energy changed $(\Delta G)$ when an infinitesimally thin layer (out of a solid with composition $\left.X^{\alpha}\right)$ with composition $X_{i}$ was transferred to a liquid with composition $X^{\mathrm{L}}$ (Fig. 10(a) ${ }^{[24]}$ ). The total decrease in Gibbs energy can be expressed by Equation (5):

$$
\Delta G=\left(1-X^{\alpha}\right)\left(\mu A^{\mathrm{L}}-\mu A^{\alpha}\right)+X^{\alpha}\left(\mu B^{\mathrm{L}}-\mu B^{\alpha}\right)
$$

where $\mu$ is the chemical potential. Gibbs free energy will decrease when the $\alpha$-phase is produced. Therefore, under steady-state solidification,

$$
\begin{aligned}
\Delta G= & \left(1-X^{\mathrm{L}}\right)\left(\mu A^{\mathrm{L}}-\mu A^{\alpha}\right)+X^{\mathrm{L}}\left(\mu B^{\mathrm{L}}-\mu B^{\alpha}\right)+\left(X^{\mathrm{L}}-X^{\alpha}\right) \\
& \left(\mu A^{\mathrm{L}}-\mu A^{\alpha}-\mu B^{\mathrm{L}}+\mu B^{\alpha}\right)
\end{aligned}
$$

The first two terms of Equation (5) define the driving force required for the migration of the interface $\Delta G_{\mathrm{m}}$. The last term

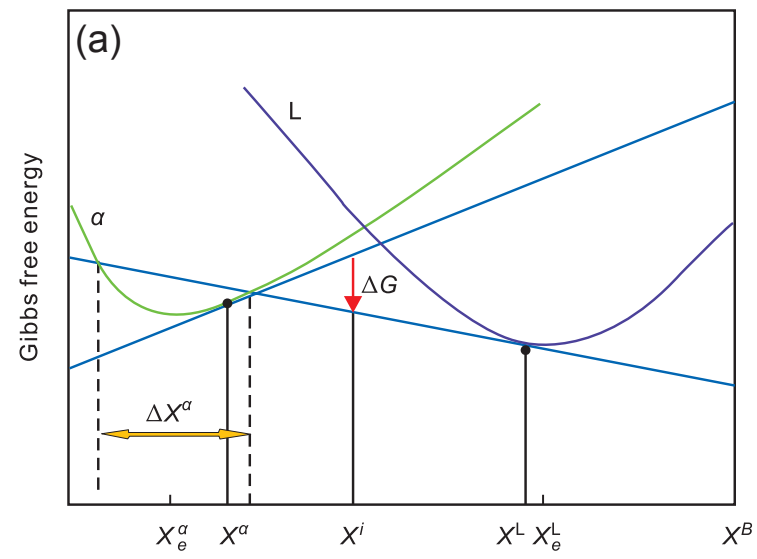

of Equation (7) signifies the change in Gibbs energy $\left(\Delta G_{t}\right)$, which is used to adjust the composition from $X^{\mathrm{L}}$ to $X^{\alpha}$ by exchanging $A$ and $B$ atoms between the two phases through diffusion across the interface. Sometimes, this process is also called trans-interface diffusion. Therefore, the total driving force required for the phase transformation can be divided into $\Delta G_{\mathrm{m}}$ and $\Delta G_{\mathrm{t}}$.

$$
\begin{gathered}
\Delta G_{\mathrm{m}}=\left(1-X^{\mathrm{L}}\right)\left(\mu A^{\mathrm{L}}-\mu A^{\alpha}\right)+X^{\mathrm{L}}\left(\mu B^{\mathrm{L}}-\mu B^{\alpha}\right) \\
\Delta G_{\mathrm{t}}=\left(X^{\mathrm{L}}-X^{\alpha}\right)\left(\mu A^{\mathrm{L}}-\mu A^{\alpha}-\mu B^{\mathrm{L}}+\mu B^{\alpha}\right)
\end{gathered}
$$

It is clear from Equation (6) that $\Delta G_{\mathrm{m}}$ is closely related to the chemical potentials $\mu_{A}$ and $\mu_{B}$ as well as to the solute concentration of the $\mathrm{S} / \mathrm{L}$ interface, whereas $\Delta G_{\mathrm{t}}$ is associated with the concentration gradient and the chemical potentials $\mu_{A}$ and $\mu_{B}$.

Figure 14(b) represents the Gibbs free-energy curve of the CDS sample. At the solid-liquid interface of the CDS sample, both sides ( $\alpha$ and $L$ ) had a lower solute concentration as compared to the CC one which could be deduced from Fig. 5; hence, its $X^{\alpha}$ (denoted as $X^{a^{\prime}}$ ) and $X^{L}$ (denoted as $X^{L^{\prime}}$ ) are smaller than those of the CC sample [Fig. 14(a)]. Due to a smaller solute gradient at the $\mathrm{S} / \mathrm{L}$ interface, the CDS sample yielded lower $\Delta G$ (defined as $\Delta G^{\prime}$ ) as compared to the CC sample, thus atoms easily migrated between the solid phase and the liquid phase; hence, the driving force required for the

Fig. 14: Gibbs free energy diagram: (a) CC; (b) CDS 
migration of the interface $\Delta G_{\mathrm{m}}$ was reduced. Moreover, the solute gradient $X^{L}-X^{\alpha}$ was reduced during the solidification of the CDS sample, thus causing a decrease in $\Delta G_{\mathrm{t}}$. As $\Delta G=\Delta G_{\mathrm{m}}$ $+\Delta G_{\mathrm{t}}$, the value of $\Delta G$ was also decreased. This indicates that the thin layer of the $\mathrm{S} / \mathrm{L}$ interface in the $\mathrm{CDS}$ sample required a much lower driving force as compared to the CC sample. In addition, the range of $\Delta X^{x}$ became wider, which made the nucleation stable at the initial stage and generated more crystal nucleus in the melt. Hence, it can be inferred that the primary $\alpha$-phase of the CDS sample required a low $\mathrm{S} / \mathrm{L}$ interface energy to generate small globular grains effectively.

The values of $\Delta G_{\mathrm{m}}$ and $\Delta G_{\mathrm{t}}$ of the CDS sample are smaller than those of the $\mathrm{CC}$ sample. Moreover, the negative concentration gradient at the grain interface of the CDS sample is much smaller than that of the $\mathrm{CC}$ sample. Therefore, during line scanning, the changes in concentrations of $\mathrm{Al}, \mathrm{Zn}, \mathrm{Mg}$, and $\mathrm{Cu}$ atoms in the CDS sample were more gentle than in the CC sample.

\subsection{Differences in primary $\alpha-A l$ phase morphology between CC and CDS samples}

The primary $\alpha$-Al phase of the CDS sample yielded a refined, non-dendritic morphology ${ }^{[24]}$, whereas the primary phase of the CC sample mainly consisted of dendrites. Grain morphology is generally related to solute and temperature gradients of the primary phase of an alloy. Figure 15 shows the schematic diagram of the growing environment of $7075 \mathrm{Al}$ subjected to $\mathrm{CC}$ and CDS. The solute gradient [Fig. 15(b)] and the temperature gradient [Fig. 15(c)] at the primary phase surrounding the
7075 aluminum alloy are higher than in CC [Fig. 15(b') and 15( $\left(\mathrm{c}^{\prime}\right)$ ]. During solidification, solute atoms diffused from the matrix of the primary phase to the $\mathrm{S} / \mathrm{L}$ interface of higher solute and temperature gradients; however, convection significantly decreased the gradients of solute and temperature at the $\mathrm{S} /$ L interface. Moreover, solute atoms were concentrated in the dendrite arm space and easily formed a high "constitutional supercooling" region [Fig. 15(a)]. As the concentration of solute atoms at the dendrite tip of the CC sample was limited, the growth rate of primary dendrites was much faster than others, and the growing rate of the primary dendrite arm at the dendrite tip was found to be the fastest [Fig. 15(d)]. However, in other regions (especially at the dendrite root), the growing of dendrites was very slow, because high element concentrations impede the grain growth. Moreover, during solidification, a significant amount of heat is generated at the $\mathrm{S} / \mathrm{L}$ interface. If the accumulated heat at the dendrite root is not discharged promptly, the secondary arm will be melted and, consequently, heat transfer will occur from the primary phase to the liquid phase. If the liquid does not cause strong convection, heat will gather at the $\mathrm{S} / \mathrm{L}$ interface and will restrict the grain growth. In contrast, due to lower solute concentration and heat accumulation, the growth rate of primary dendrites at the dendrite tip was high, thus resulting in a well-developed, dendritic morphology. However, during CDS, the solidification environment caused strong convection, which easily diffused the accumulated solute atoms and heat at the $\mathrm{S} / \mathrm{L}$ interface. The gradients of solute and temperature became more uniform by convection. Thus, the primary phase attained a near-spherical shape [Fig. 15(d')].
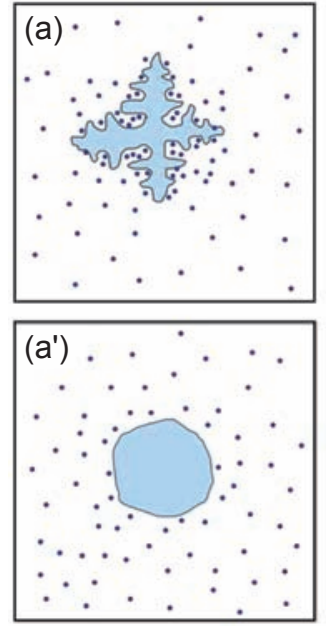
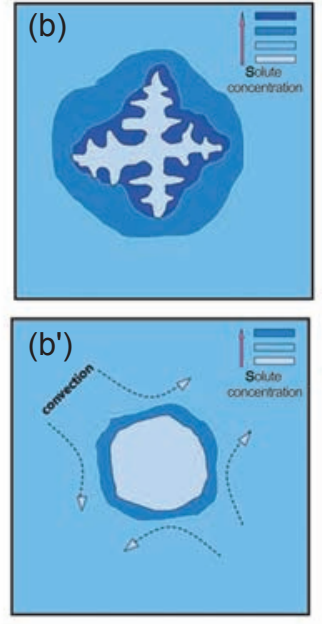
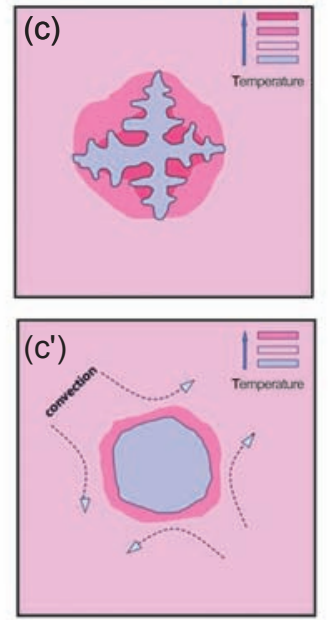
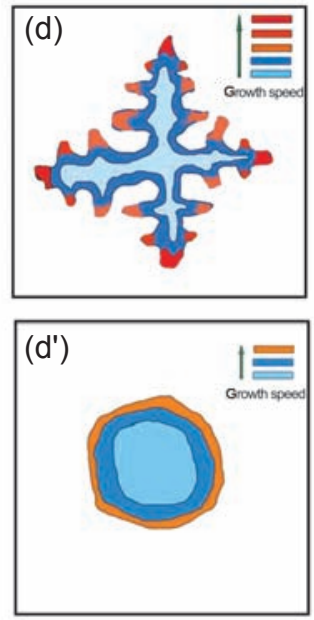

Fig. 15: Growing environment schematic diagram of 7075 aluminum alloy by CC and CDS

\subsection{Differences in eutectic phase morphology between CC and CDS samples}

During eutectic reaction, due to the continuous decrease in solidification temperature, eutectic phases were generated in interspaces of the primary phase. In contrast, the solute and the temperature gradients of the CC sample were large due to its poor heat convection ability. Therefore, the amounts of $\mathrm{Zn}, \mathrm{Mg}$, and $\mathrm{Cu}$ atoms (except for $\mathrm{Al}$ ) in the $T(\mathrm{Al}-\mathrm{Zn}-\mathrm{Mg}$ -
$\mathrm{Cu}$ ) phase were lower than those in the CDS sample. The presence of a solute concentration layer at the $\mathrm{S} / \mathrm{L}$ interface of the $\mathrm{CC}$ sample prevented the supply of $\mathrm{Al}$ atoms from the $\mathrm{S} / \mathrm{L}$ interface to the primary phase, thus the content of $T(\mathrm{Al}-$ $\mathrm{Zn}-\mathrm{Mg}-\mathrm{Cu}$ ) phases in the $\mathrm{CC}$ samples was lower than that in the CDS samples. Hence, the eutectic phase of the CC sample mainly consisted of lamellar eutectics. In contrast, during solidification, the CDS sample showed a stronger heat 
convection ability and did not create an effective "constitutional supercooling" region. Due to high $\mathrm{Zn}, \mathrm{Mg}$, and $\mathrm{Cu}$ contents, the eutectic phases of the CDS samples were composed of rodlike eutectics. Moreover, the thin solute-concentration layer of the CDS samples showed a gradual compositional fluctuation at the $\mathrm{S} / \mathrm{L}$ interface during solidification and impeded the formation of cracks. Therefore, it can be inferred that the nondendritic primary phase and the rod-like microstructure play a positive role in achieving improved tensile properties.

\section{Conclusions}

(1) The CC sample yields a well-developed dendritic morphology with a large amount of shrinkage porosity; thus, it easily generates dendrites from the liquid phase. However, the primary $\alpha$-Al phase of the CDS sample shows a homogeneous, non-dendritic microstructure. The XRD analysis reveals that the constitutions of the CC and the CDS samples were almost the same.

(2) During the solidification of the CDS sample, due to a much lower driving force (as compared to the CC sample), stable primary grains were developed in every direction of the thin S/L interface layer. Moreover, the primary $\alpha$ nuclei of the CDS sample were found to be more stable at the initial stage.

(3) The average tensile strength and elongation of the ascast CDS sample were found to be superior to those of the CC samples. The T4 treatment for $60 \mathrm{~min}$ yields the highest elongation, whereas the $\mathrm{T} 6$ treatment has the best tensile strength. The amount of shrinkage porosity in the CDS sample was significantly reduced under different heat treatment conditions.

(4) The eutectic phases of the CC and CDS samples were mainly composed of lamellar eutectics and rod-like eutectics, respectively. Lamellar eutectics act as crack initiation sites during the tensile test, thus resulting in relatively poor tensile properties, whereas rod-like eutectics show a superior tensile force-resisting capacity.

\section{References}

[1] Dursun T, Soutis C. Recent developments in advanced aircraft aluminium alloys. Materials \& Design, 2014, 56: 862-871.

[2] Williams J C, Starke A J E. Progress in structural materials for aerospace systems. Acta Materialia, 2003, 51(19): 5775-5799.

[3] Andrzejewski D, Jakubowicz J, Borowski J. Structure and properties of 7075 products obtained with the KOBO method aluminum alloy. Archives of Civil and Mechanical Engineering, 2016, 16: 217-223.

[4] Huo W T, Hou L G, Lang Y J. Improved thermo-mechanical processing for effective grain refinement of high-strength AA7050 Al alloy. Materials Science \& Engineering: A, 2015, 626: 86-93.

[5] Li X W, Cai Q Z. Effect of nano TiN/Ti refiner addition content on the microstructure and properties of as-cast $\mathrm{Al}-\mathrm{Zn}-\mathrm{Mg}-\mathrm{Cu}$ alloy. Journal of Alloys and Compounds, 2016, 675: 201-210.
[6] He Y D, Zhang X M, You J H. Effect of minor Cr, Mn, Ti and Zr on microstructure and mechanical properties of $\mathrm{Al}-\mathrm{Zn}-\mathrm{Mg}-\mathrm{Cu}$. The Chinese Journal Nonferrous Metals, 2005, 15 (12): 1917-1924.

[7] Gao Z H, Xu J, Zhang Z F. Effect of annular electromagnetic stirring melt treatment technology on solidification behavior of 7075 aluminium alloy. Special Casting \& Nonferrous Alloys, 2015, 35 (1): 5-8.

[8] Lin C, Wu S W, Lü S L, et al. Microstructure and mechanical properties of rheo-diecast hypereutectic Al-Si alloy with $2 \% \mathrm{Fe}$ assisted with ultrasonic vibration process. Journal of Alloys and Compounds, 2013, 568: 42-48.

[9] Langford G, Cunningham R E. Steel casting by diffusion solidification. Metallurgical Transactions B,1978, 9(1): 5-19.

[10] Langford G, Apelian D. Diffusion solidification. Journal of Metals, 1980, 32 (9): 28-34.

[11] Saha D, Shankar S, Apelian D, et al. Casting of aluminum based wrought alloys using controlled diffusion solidification. Metallurgical and Materials Transactions A, 2004, 35 (7): 21742180.

[12] Abbas K, Peyman A, Sumanth S. Formation of nondendritic primary aluminum phase in hypoeutectic alloys in Controlled Diffusion Solidification (CDS): a hypothesis. Metallurgical and Materials Transactions, 2009, 40B: 843-849.

[13] Khalaf A A, Shankar S. Effect of mixing rate on the morphology of primary Al phase in the controlled diffusion solidification (CDS) process. Journal of Materials Science, 2012, 47: 8153-8166.

[14] Li Y D, He M T. Effects of mixing melt treatment and heattreatment on the microstructure and wear resistance of $\mathrm{Al}-22 \% \mathrm{Si}$ alloys. Advance materials research, 2013, 815: 195-200.

[15] Li D, Zhang X L, Ma Y, et al. Effect of mixing rate and temperature on primary Si phase of hypereutectic Al-20Si alloy during controlled diffusion solidification (CDS) process. China Foundry, 2015, 12(3): 173-179.

[16] Mondolfo L F. Metallography of Aluminum Alloys. Nabu Press, Charleston, USA, 2011.

[17] Teng H T, Xiong B Q. Solidification microstructure of high zinccontaining Al-Zn-Mg-Cu Alloys. The Chinese Journal Nonferrous Metals, 2015, 25 (4): 852-865.

[18] Fan X, Jiang D, Meng Q. The microstructural evolution of an AlZn-Mg-Cu alloy during Homogenization. Materials Letters, 2006, 60 (12): 1475-1479.

[19] Lin G, Zheng X, Yang W. Study on the hot deformation behavior of Al-Zn-Mg-Cu-Cr aluminum alloy during multi-stage hot compression. Acta Metallurgica Sinica, 2009, 22 (2): 110-116.

[20] Xiao S X, Wang C Y, Chen L. The Application of the Discrete Variational Method in the Density Functional Theory to Chemistry and Materials Physics. Science Press, Beijing, China, 1998.

[21] Liu G L, Fang G L. Grain-boundary segregation and corrosion mechanism of $\mathrm{Al}-\mathrm{Zn}-\mathrm{Mg}-\mathrm{Cu}$ ultrahigh strength aluminum alloys. Rare Metal Materials and Engineering, 2009, 38 (9): 1598-1602.

[22] Baker J C, Cahn J W. The Thermodynamics of Solidification, In: Proc. ASM seminar series on "Solidification", Metals Park $\mathrm{OH}, 1971:$ 23-58.

[23] RettenmayrM. Melting and remelting phenomena. International Materials Reviews, 2009, 54 (1): 1-17.

[24] Ghiaasiaan R, Zeng X C, Shankar S. Controlled Diffusion Solidification (CDS) of Al-Zn-Mg-Cu (7050): Microstructure, heat treatment and mechanical properties. Materials Science \& Engineering A, 2014, 594: 260-277. 